\title{
International Accreditation of PA Programs: Narrations of an Evaluator
}

Michiel S. de Vries

\section{Introduction}

This paper addresses the strengths and weaknesses of the current system of accreditation of PA programs and the ways these weaknesses can be resolved. What are the challenges facing accreditation in PA today?

In order to answer that question; this paper will first address the goals of accreditation processes as mentioned in the relevant documents of the three organizations involved in accreditation, that is EAPAA (The European Association for Public Administration Accreditation ${ }^{1}$ ), NASPAA (the accreditation organization for PA programs in the USA ${ }^{2}$ ) and CIAPA (the recently established accreditation organization for accreditation of public administration programs within the International Association of Schools and Institutes in Administration ${ }^{3}$ ). This does not imply that these are the only organizations accrediting public administration programs. In some countries national governments do not accept international accreditation (e.g. by EAPAA) for funding. In such countries, this has to be done by a national authority. This distinction is, however, not crucial for the argument given below. This article addresses the problem of program accreditation in public administration as such, irrespective of whether it is done by a national or an international organization. Furthermore, the procedures for both international and national accreditation are often similar.

The process of accreditation is mostly standardized: the board of the accreditation organization in question makes a decision to accredit or not to accredit a program in public administration that has requested such accreditation. The request is based on a report from a site-visit team of international experts in public adminis-

1 http://www.eapaa.org/

2 http://www.naspaa.org/

3 http://www.iias-iisa.org/iasia/e/CIAPA/Pages/default.aspx 
tration and peers that has examined the quality of the program during a short visit to the university and its judgment of a previously written self-evaluation provided by the institute requesting accreditation.

Next we will address the weaknesses of the accreditation process as it exists nowadays. Many of these weaknesses are well-known (cf. Reichard 2010), and procedures have been adapted in the past to address these problems.

Basically the issue this paper addresses can be defined as follows: Seen on a continuum one can distinguish between a variety of programs, some being excellent, others good and still others adequate or even unsatisfactory. Secondly there are decisions by the boards of accreditation organizations whether or not to accredit such programs. If a bad program is denied accreditation or an adequate/good/excellent program is accredited, there is no problem. The crucial question is how to prevent that accreditation is denied to good programs and accreditation is granted to programs that do not deserve it. It is comparable to hypothesis testing in which a true hypothesis is falsified and a false hypothesis is supported, i.e. $\alpha$ and $\beta$ errors.

In theory such errors are to be prevented by setting clear criteria and following the procedures in use within the accreditation organizations, guaranteeing that such decisions are based on honest self-evaluations about a program's quality and a thorough inspection of its quality by experts in the field. Since the start of accreditation, most operational problems faced in this process of judging self-evaluations within the limits of a two-day visit have been addressed. This paper does not argue that the operational problems have disappeared. It will even give recent examples thereof. However, the increasing experience of members in site-visit teams has diminished the challenge such problems cause.

An emerging issue is, however, that because of the apparent operational problems in accreditation - even though these are often easily debunked by the site-visit team -, the advice of the team of experts seems to become less important for the final decision on accreditation, compared to the strategic interests of the institute requesting accreditation. This increases the probability of $\alpha$ and $\beta$ errors.

This paper is not the first to question the accreditation procedure (see for instance Reichard 2010). However, it does make the challenges very concrete by illustrating them with personal experiences, and it points to a dangerous tendency in the decision-making process to abuse the substantive operational issues as strategic arguments in an attempt to influence the final decision.

If this argumentation is accepted, and this paper will try its utmost to illustrate the challenges in such a way that there can be no denial of their existence, the question arises what to do. This is the issue addressed in the last part of this paper. First of all the goals and merits of accreditation will be discussed in order to show that this paper starts off from a positive inclination towards accreditation and peer review. 


\section{The merits of accreditation in public administration}

For NASPAA, being accredited has value especially for potential students, employers and peers. Its website tells us: "NASPAA accreditation is an external stamp of program quality". Accreditation makes a distinction between two categories of institutes based on whether or not they have quality, strive for improvement and have public-service education as their core business sure (http://www.naspaa.org/ accreditation/ns/seek.asp). Christoph Reichard, who is more involved in EAPAA, mentioned several purposes for such EAPAA accreditation (Reichard 2010). He states that in some countries accreditation is mandatory to get funded. Employers value students from accredited programs higher. It also has a legitimizing effect implying that the curriculum maintains a certain level of quality. Furthermore it safeguards the identity and integrity of the discipline and supports the further development of PA as a discipline within the social sciences. Also it can result in convergence and a common understanding of PA between and within universities (Reichard 2010, 47-48). The necessary components of a good PA program show what should be addressed in order to be accredited, such as management and organization, problem-solving, leadership, research techniques, public policy and institutions, public-sector ethos and skills (cf. Task Force on Standards of Excellence 2008, 9-11). In 2013, one may argue that accreditation is also a must for programs that want to join international cooperation, in which such accreditation is usually required.

A positive outcome of accreditation processes is not the sole advantage for PA programs. The process before the accreditation starts is seen as being of utmost importance for the improvement of the quality of the program. Because of the reflection on the program, which is necessary in order to write an adequate self-evaluation, amendments in programs are made. The critical review of teaching and facilities and the quality of the management of the curriculum itself is of value for PA programs. The most important merit of accreditation processes is that they force schools to reflect on what they are doing, to investigate the choices in the curricula that are necessarily made, given the impossibility to include everything in a program which is limited in time (3 years for a bachelor and 1-2 years for a master) and to find-out where things proceed as they should and where improvements are needed.

The accreditation of public administration programs forces schools to reflect on all this, based on what they themselves say they want to accomplish, i.e. their mission. It is their responsibility to make sure that the mission is indeed accomplished through everything offered to their students. This involves the sufficiency of the contents of the curriculum, whether there is qualified and ample staff to train the students adequately, whether the program is feasible in time, whether the facilities offered are adequate and whether the grading of exams does justice to the learning, the acquired skills and development of an academic attitude of their students, 
to name just a few of the criteria used. Especially this process before the accreditation starts is seen as being of utmost importance for the improvement of the quality of the program.

Where the above-mentioned purposes are dominantly outcome related in terms of added value for the program being accredited, accreditation can also be seen as a tool that is beneficial for the students, the employers and society as a whole in a normative way. In the recently established CIAPA, such process criteria are central. Blue Wooldridge (Task Force on Standards of Excellence 2008), one of the instigators of the UN/IASIA Standards of Excellence proposes that accreditation should assess excellence in public administration education and training by the commitment thereof to a clearly described vision and mission, a focus on quality services for the client, empowerment of employees, valuing diversity and communicating effectively.

This should be visible in the faculty's fundamental commitment to public service in all of their activities. It should be to the advancement of the public interest and the building of democratic institutions; to the advancement of public service by both their advocacy for and their efforts to create a culture of participation, commitment, responsiveness and accountability; to the integration of theory and practice and the need to have a program that draws upon knowledge and understanding generated both by the highest quality of research and the most outstanding practical experience. Wooldridge also mentions the need for an unwavering commitment to diversity of ideas and of participation on the part of the faculty and administration. The people who participate in programs, including students, trainees, trainers, administrators and faculty, should come from all different racial, ethnic and demographic communities of the society. According to Wooldridge it is essential for those who educate and train public administrators to communicate, work with and, to an appropriate degree, be responsive to the organizations for which they are preparing students and trainees, ensuring that there are adequate resources, including facilities, technology, library resources and student services. (Task Force on Standards of Excellence 2008, 5-6).

NASPAA formulated four more formal basic preconditions for its accreditation: program eligibility, including that the institution offering the program is accredited, a fixed mission in which public-service values are central, a focus on preparing students to become leaders, managers and analysts, and a minimum length of the studies. Such preconditions ensure that formal conditions are met and that only programs in public administration can apply and no other social sciences with a major in PA (cf http://www.naspaa.org/).

The first preliminary conclusion cannot but be that accreditation is intended to have many merits for the development, legitimacy and contents of programs in public administration education. Basically, the idea is that the accreditation of a program tells me as a father whether I should be pleased if one of my children opts 
to study in such a program, and it tells me as a department chair whether a request by a student who wants to spend a semester to study in such a program should be granted. But does it?

\section{The known operational challenges in accreditation}

This section addresses some of the operational challenges in program accreditation. It follows the sequence in the accreditation process, starting with the request to be accredited, and subsequently addresses the writing of the self-evaluation and the inquiries by a site-visit team.

\subsection{Requesting accreditation}

In order to get accredited, a program first has to make a request. Since many academic disciplines have their own accreditation organization, it makes sense to make the request within the discipline of the program in order for programs in economics to get accreditation in economics while a public administration program asks for accreditation in public administration. This is what Reichard called the function of accreditation as safeguarding the identity and integrity of the discipline and supporting the further development of PA as a discipline within the social sciences (Reichard 2010, 47-48).

Two challenges are known in this respect:

The first is related to the following: The opinions on how the discipline of public administration should be framed vary over countries. In some countries the study of public administration has its origins mainly in faculties of law, in others the connection with political science is much stronger, and in still others there is an origin in business administration and economics. Geörgy Hajnal (2003) divided public administration programs into a business group, a policy/administration group and a legal group of PA curricula. According to Hajnal, the business group was dominant at the time in Denmark, Norway, Latvia, the Czech Republic, Slovakia and Armenia. The emphasis on legal issues was found especially in Poland, Hungary, Romania, Yugoslavia, Portugal, Italy and Greece. The policy group with an emphasis on political issues was found in the remainder of continental Europe.

A second important discussion - also partly based on national traditions - concerns the question what constitutes a good study in public administration. This discussion concentrates on the classic question whether a program offers a study of public administration or for public administration (cf. Robson 1975, 71). Is the education in public administration to be seen as preparation and training to become a leader, manager or analyst in the public sector, and does the program educate for public employment, or do such programs educate their students to become academics and to offer public administration as a scholarly discipline, or - as a third possibility as 
some put it - to become something in between as a pracademic (cf. Posner,200)? The question originates from the classic discussion whether the study in PA is conceived as an art (that is, philosophizing about), as a craft (that is, practical use), or as a science (that is, systematic investigation of reality for theory development) (Raadschelders 2011).

This has long been one of the main points of discussion in public administration, about which famous scholars have written, among them Waldo (1948), Stillman (1997), Wengert (1942), Pollitt (1996), Rhodes (1991), and Raadschelders (2011). The discussion of this distinction revealed nationally bound traditions, i.e. a US tradition and a European tradition, and within Europe continental, UK and Scandinavian traditions, although the position of PA programs in the different countries is not entirely clear. Some see the dominant education in PA in the USA as much more pragmatic than the schools in Europe. This is argued, for instance, by Raadschelders (2011, 146-147), stating that the research and teaching in American public administration has a much stronger practical orientation, visible in the numerous case studies published in the literature and the use of case studies in textbooks. It is also visible in the emphasis of curricula across the nation on practical skills (for example, budgeting and finance, personnel management, program evaluation, performance management and so on), whereas European curricula in public administration generally would focus more on philosophy, political theory and history.

However, Fritz Morstein Marx, writing about German PA programs, argues the opposite, namely that there are different traditions in the study of public administration with the legal tradition in continental Europe, the pragmatic tradition in the UK and the American tradition towards science (Morstein Marx 1967).

Partly these differences are reflected in educational systems, in the emphasis on knowledge or skills, academic or pragmatic attitudes, the dominance of discussing the outcomes of case studies or on teaching students how to conduct research, be it a case study or quantitative research, the importance of having an internship or even previous experience as a public official et cetera.

Partly the differences can be pinpointed to specific levels of education. In Europe, bachelor programs are often disciplinary, and students immediately enroll in the master program after finishing the bachelor, while in the USA bachelor programs are often more general/interdisciplinary, and students work a couple of years in the public sector after obtaining their bachelor degree before entering a master program in PA, making the differences largest in master programs, while Ph.D. programs everywhere emphasize the study of public administration.

Such discussions are not problematic within the discipline and even fruitful for its further developments. Viewed from the outside, such discussions could tempt programs in related but nevertheless distinct disciplines to ask for accreditation within the domain of public administration, although they are in reality pro- 
grams in economics, law, sociology, political science or even developmental studies. If the only goal is to be accredited, no matter where and how, a program is inclined to seek accreditation by an organization from which a positive outcome is the most likely. This would not be a problem if the accreditation in all disciplines had equal criteria and the procedures were comparable, and within the disciplines national and international accreditation were equally challenging. This is, however, not the case. The status of our discipline in the whole of scholarly programs is not such that it is seen as the most advanced discipline.

Accreditation in public administration seems for some people to have an image of a light version of accreditation. I have seen programs in law incorporating only one course of three ECTS in organization and management, and this even reluctantly because according to the program leadership the three ECTS could be used much better in the training of yet another subject in law. The course was only included because it was thought that on this basis an accreditation in public administration could successfully be requested. And I have been involved in the accreditation of programs in economics, reluctantly changing the names of their courses from economics into courses in policy-making, in order to be accredited in public administration.

In both cases the system of accreditation worked out in the end, but the resulting warning is that we should stay aware of the challenge involved in the aim that accreditation results in a demarcation of the subject of public administration and acts as a safeguard for the identity and integrity of the discipline. This assumes that there is something like an identity and integrity thereof. In my experience, not everybody is equally convinced that this is actually the case.

The examples are indicative of an image of an ambiguous nature of public administration and of (Inter-) national accreditation in this discipline, i.e. that it is inclusive, instead of being selective in establishing a company of institutes that upholds the values involved in the education in public administration.

\subsection{Writing a Self-Evaluation}

The basis of each accreditation process is the self-evaluation of the program to be evaluated. Christoph Reichard (2010) has already made some valuable comments about the operational challenges involved in judging self-evaluations. On the one hand he quotes a survey among managers of such programs stating that the selfevaluation forced them to ask some uncomfortable question and that the accreditation opened a window of change as evaluators asked for certain improvements. This could benefit the quality of programs.

On the other hand Reichard mentions the weaknesses of the procedure. Evaluators have to believe the self-evaluation and can only verify a few issues within the two-day visit. Although evaluators in general have the impression they get a "true 
picture", it may be questionable to which extent their picture of the program is valid and complete (Reichard 2010,48).

An illustration of this point, based on my own experience, is a self-evaluation of an Asian academy asking for my advice. They had used the UN-IASIA standardsof-excellence framework, but instead of giving an account of what they were doing, they just filled in the scores on the list of criteria by which to assess progress on the standards in the form of four-point Likert-scale items. As they mentioned, they were forced to adapt the Likert-scale, even though it was judged not to be specific enough for their purposes. It needed to be a six-point scale instead of the four-point scale. After they had scored their programs on all criteria, it proved that all of the scores were sixes, except for one 5.75 on which they promised to make improvements as soon as possible.

Another example illustrating that a verification of the self-evaluation is needed, is that in discussing the merits of a similar national academy in an Asian country, the self-evaluation stated that the program gives much attention to the education and training of norms and values in public administration. Nearly every course was said to touch upon these important issues. Because it is one of my main topics of interest and I am still not sure how to train students to become integer officials in the public sector, I asked what it was the program actually did in this respect. It appeared that value in public administration was interpreted as the economically added value of the public sector, and norms referred simply to expected achievements/input-output standards based on performance measurements. This was not at all expected of a definition of norms and values in terms of rule of law, democracy, integrity, transparency and other indicators related to ethics. The faculty seemed as flabbergasted by my interpretation of norms and values as I was about their interpretation thereof.

Such misunderstandings could be seen as posing only a problem if the program is in a country, language and culture unknown to the evaluators. However, also figures and tables can be ambiguous. To mention only the simplest table on student-staff ratio, many a problem can arise. Is staff the number of people working in the faculty? Is it just the part of their job devoted to lecturing that is to be incorporated, or is the staff's research time also included? Is it just tenured staff, or do the tables include Ph.D. students and guest lecturers? The same goes for the number of students. Does their number include drop-outs, part-time students et cetera? The problem is not that different definitions are possible and used in different countries, but that it is not always clear what definition is actually used, rendering it harder to make valid judgments about the adequacy of the tables as well as about the studentstaff ratio as such. Of course there are standards of such tables, but they evoke a lot of criticism because of the needed paper-work.

Notwithstanding such obscurities in many a self-evaluation, the strengths and weaknesses of programs often do become apparent during the site visits. Experi- 
enced evaluators know the problems that each program by definition faces, because there are insolvable dilemmas, so that any self-evaluation that just mentions the program being perfect cannot be expected to have given a "true" account thereof.

The third preliminary conclusion is that self-evaluations can only to be trusted to a certain degree and that site visits are therefore crucial.

Site-visit teams are usually composed by an international committee of peers, that is, they come by definition from different countries and universities. One of the known challenges is related to the fact that the traditions vary regarding the way that public administration is educated at the universities that scholars come from. As mentioned above, in some countries the study has its origins mainly in faculties of law, in others the connection with political science is much stronger, and in still others it originates in business administration and economics.

A strict division between countries is not possible, because in many a country, and especially in Western European countries, an emancipation of public administration away from the basic disciplines took place - for instance in Germany away from law schools and in the Netherlands away from political science. Nonetheless, varying traditions still impact on the views of scholars from such countries and hence on the emphasis they - as members of a site-visit team - put on necessary aspects of PA programs. A recurring discussion in all the teams the author was part of concerned the question whether a program contains enough economics, political science, law or sociology. Many reports contain recommendations to include one of these subjects if it is missing or to put more emphasis on such subjects in case the topics are covered only by one or two courses. This variance is not just seen between countries; there are also differences within countries. Nonetheless the variance should not be exaggerated. If the site-visit team is indeed international such remarks are often mitigated within the site-visit team or, later on, by the board of the accreditation organization. The differences are also reflected in the accreditation criteria of EAPAA, NASPAA and CIAPA.

In NASPAA the two main substantial prerequisites for being eligible for accreditation is to have a mission in which public-service values are central and a focus on preparing students to become leaders, managers and analysts, whereas in EAPAA the emphasis is much more on advancing academic knowledge and skills.

In CIAPA the prerequisites seem to have become a mixture of both traditions. It aims at setting prerequisites in the faculty's fundamental commitment to public service in all of their activities; to the advancement of the public interest and the building of democratic institutions; to the advancement of public service by both their advocacy for, and their efforts to create, a culture of participation, commitment, responsiveness and accountability, as well as the requirement that the program integrate theory and practice and the need to have a program that draws upon knowledge and understanding generated both by the highest quality of research and the most outstanding practical experience. 
Such differences between accreditation organizations and between individual experts in the field about what constitutes an excellent study in public administration, are often hardly a problem in the practice of site-visits. They rather result in nice discussions within site-visit teams and between site-visit teams and faculties of programs to be accredited, and they are almost never determinative for the positive or negative advice regarding accreditation.

Simultaneously the above discussion results in the fourth preliminary conclusion that there are indications supporting the image that the judgment of programs in PA is not only dependent on the quality thereof, but also could be dependent on different opinions about what constitutes a decent program in public administration.

\section{The transposition of operational challenges to strategic arguments}

As mentioned above it is advantageous for programs to be accredited. It ensures funding and legitimacy. European funding programs increasingly require accreditation to provide funds, such as Erasmus Mundus; and national government frequently requires a program to be accredited as a precondition to give grants to enrolled students, to finance the programs and to certify the diplomas. In such situations, accreditation is a necessity for the continuation of programs. Hence, huge interests are at stake in the accreditation of academic programs.

Such interests can result in a substitution of substantive by strategic argumentation and could imply that the outcome of accreditation procedures is not just determined by the quality of the nature of the program and whether the program fulfills the requirements set by the accreditation organization. Strategic interests, which ideally should not play a role, might nevertheless affect the decision taken about accreditation, thus increasing the probability of the previously mentioned $\alpha$ and $\beta$ errors.

This section will present an example showing that this does indeed happen in practice and, moreover, that the points discussed about accreditation in public administration are in practice transformed from substantial challenges in the process of accreditation in PA into strategic arguments to enforce disputable decisions about accreditation.

It is a case study from the home country of the author. A renowned institute of social studies asked for accreditation for a new international master in public policy. I was asked to chair the international site-visit team. As soon as the self-evaluation was read, the site-visit team members convened and asked each other what to think about a program with the title "master in public policy" having less than $5 \%$ of the 120 ECTS in the total program addressing public policy and the course in this subject being taught by guest lecturers. The site-visit team got the impression that 
it was comparable to the programs mentioned before, a program with a really good reputation in its own discipline, that is developmental studies, assuming that adding one course in public policy would qualify the program for getting accredited in PA. During the site visit the faculty was asked why they wanted an accreditation within the domain of public administration under this label. It appeared that the idea within the faculty was that this was the easiest way to get accredited quickly, which was necessary because a huge EU fund was dependent on getting accredited.

At first sight the system again seemed to work, because the site-visit team was critical about the gap between the title and mission of the program and its contents. It concluded that this program under this heading was inadequate, and it advised that the program should not be accredited. One can imagine that this outcome and the delivery of the decision at the end of the site-visit resulted in a somewhat awkward reception at the end of the two-day visit.

This was not the only thing awkward about this procedure. Even before the final report was delivered, the institute requested a re-accreditation of the same program. As chair of the site-visit team I got a telephone call by a representative of the Dutch Flemish Accreditation Committee (NVAO), telling me that the director of the institute of which the program was assessed had a meeting with the president of the NVAO. They decided amongst themselves that the negative conclusion of the site-visit team could not have been caused by the poor quality of the program and had to be the consequence of different views on the definition of public policy between the institute and the site-visit team.

Furthermore, there were serious interests at stake, such as money of the EU regarding Erasmus Mundus funds, which would only be disbursed if the program was indeed accredited. Hence there had to be a quick re-accreditation process. Although I did not mention anything about being chair of the new site-visit team or my ideas about being a member thereof, I was made to understand beforehand that my chairmanship was not really appreciated anymore. To quote: "The accreditation organization can imagine that this article, $\mathrm{MdV}$ ] would not be interested to conduct that re-accreditation and we [that is the NVAO, MdV] would certainly respect such a withdrawal of the chair." A couple of days later the president of the organization, a former Dutch politician, sent an e-mail stating: "We have noticed that you seriously doubt whether this program can realize its ambition as a program in Public Policy. The program also interpreted your opinion as such. Therefore, the Board of Management seriously doubts whether you (and the program) should be brought in the position to judge the program again ... As an accreditation organization we cannot beforehand display a judgment about the appropriateness of the name and contents of the program" and again: "If you would withdraw from the site-visit team involved in re-accreditation, we would fully understand." 
In other words, that the program received a negative review of the site-visit team is not to be blamed on the program, and we don't want you to be a member, let alone to be chair of the panel again.

Upon my reply that "I would not consider it chic if basically the same program would be accredited in a re-assessment, only because of a personal meeting between the director of the institute and the president of the accreditation organization and a different composition of the panel", the mail exchange becomes nasty. With many exclamation marks in an overawing e-mail, the president of the Dutch accreditation organization responds: "You should not misapprehend!" and "There should not be any repetition!" "There should be a new self-evaluation report. Not just a cosmetic change!" "We do nót [emphasis in the mail, $M d V$ ] doubt your independent judgment ... bút [ibid] we do see a firm discussion about the nature of public policy."

To sum up the aftermath, even before the final report of the first site-visit team was sent to the accreditation organization, the program requested accreditation again. The accreditation organization granted this to the program, and within two months the program was visited by a new team and it accredited the program immediately. The EU funds were secured. At my request afterwards to see the adjusted self-evaluation of the institute, the accreditation organization responded that such documents are confidential. At my remark that as a chair of the first site-visit team, I had already seen all confidential parts in the first self-evaluation, that I only wanted to see whether there were indeed more than just cosmetic changes in the second self-evaluation, and that I wanted to refer to this case in a publication, I have not received any response so far.

Although this is not a case of international but national accreditation, its procedure was basically the same as in international accreditation procedures with an international site-visit team. In this case all the images of PA accreditation as mentioned in the previous sections were at a higher level of decision-making used strategically to enforce the decision to accredit the program under review. This concerns the varying opinions about the nature of public administration, the possible impact of the composition of a site-visit team on the assessment, the limited possibilities for a site-visit team to investigate the "true" nature of a program within two days, and the contents of a self-evaluation, which apparently can be adapted within days in order to convince an accreditation organization that the program should be accredited as a PA program.

The substantial challenges mentioned in previous sections were transformed into strategic arguments to counter the unwelcome conclusions of the evaluators, to ensure EU funds for the program and thus to accommodate the interests of the institute and the accreditation organization. 


\section{Analysis}

The case study presented above shows that outcomes contrary to the original functions of accreditation as mentioned before by, for instance, Reichard (2010) are possible. Especially because the present form of accreditation does not always succeed in safeguarding the identity and integrity of the discipline and the further development of PA as a discipline within the social sciences. If this argument is convincing, the question arises what to do. Below three options are presented, although there must be many more.

1. The first solution is to discard accreditation procedures altogether. This point is supported by many a program that undergoes or has undergone such procedures. There are several further reasons in favor of this solution: the bureaucracy involved, especially considering the time and energy to be invested by scarce staff; the fact that the outcome of the procedure is often known already beforehand; the necessary institutional lying; the biased information to be provided; and the possibility that accreditation increasingly becomes a standard operating procedure, instead of a genuine learning process. However, given the valid aims of accreditation we need to check other alternatives before adhering to this first solution.

2. An alternative solution could be to simply do nothing. One could say that the problems are based on a single case study and the problems are not structural. At the operational level site-visit teams nowadays consist at least partly of experienced evaluators, and they know where the dilemmas lie, where a program did have to make difficult choices because of the limitations that always exist, because the means available to make an excellent program are always less than the means needed. For instance, group assignments are good to teach students to work in a project, to cooperate, to divide tasks and to make compromises, but at the same time there is an inevitable problem involved in such group work, in grading individual students for group assignments and to take precautions against free riders. There are only three years for a bachelor program and one to two years for a master, and however smart the program is composed, one simply cannot provide students with all the necessary knowledge, skills and attitudes within such a short time. Experienced evaluators know this and just want to know whether the program is aware of these dilemmas, what choices are made, why those choices are made and whether this is in line with the program's mission. The discussions within the discipline and the adapted procedures in recent years have taken care of most of the operational problems. Furthermore, one could argue that the supposed transposition of the operational issues to the strategic level is rarely seen. Sometimes a board decision and the expert's advice diverge. This is only natural since experts can also make mistakes. This can indeed be argued, because discussions about the frequency of an occurrence regard empirical questions that can only be resolved by empirical research. Such 
systematic research is needed. However, there are two counterarguments to the argument to do nothing. The first is that PA is not the only discipline where the problems mentioned are visible. Similar discussions are seen, for instance, in medical science and psychology. This leads to the question what is so special about PA that such unfortunate processes would only be rare in this discipline. The second counterargument is the strange personal observation that the more experience I got as an evaluator of PA programs, the more often I witnessed that the advice of the site-visit team I was a member of was put aside by the board of the accreditation committee.

3. This brings me to the third option. That is to change something in the process of accreditation to ensure that the role of strategic interests is minimized and to ensure that accreditation processes in practice do live up to the aims they are said to have in theory and to enable unreserved attempts to minimize $\alpha$ and $\beta$ errors. This is primarily related to the integrity in and of the process. One of the solutions well known in public administration for such problems is to increase the transparency and the checks and balances in the process. A side effect of strengthening checks and balances is that it increases the transparency of the accreditation process, because more actors are involved in each of the phases of the process. Transparency implies that things are done in the open, and this is a major obstacle for the influence of factors and actors that should not be influential.

At present there are four phases in the accreditation process: the request, the self-evaluation, the site visit and the final decision. These phases run sequential, and there are hardly any regulations about what should be done if the four phases do not concur. At present, the utilization of the possibility of having checks and balances in the procedure is substandard.

a. A preliminary check by the accreditation organization whether a program is indeed eligible for accreditation in the requested discipline is a promising solution to safeguard the identity and integrity of the discipline and to check later on in the process whether the self-evaluation is truthful. A site visit even before the self-evaluation is written, just after the request is made, could be beneficial for getting information about the program and for the program to get information about the accreditation procedure.

b. One could try to minimize institutional lying in self-evaluations by increasing the penalty if irregularities are detected by the site-visit team. Nowadays such disparities are points of discussion during site visits, but only rarely do they result in the only logical outcome, that is, to deny accreditation on the basis of such irregularities.

c. Third, the advice of a site-visit team should not easily be put aside. This should only be done if there are good arguments to do so, if the site-visit team is notified and if this decision is substantiated. Nowadays site-visit teams are 
not even notified about whatever decision is made by boards of accreditation organizations.

d. One could pursue the procedure followed by scholarly journals, which notify reviewers about the final decision taken by the editor to accept a submitted paper for publication or not. An even more transparent situation would be inviting the chair of the site-visit team to partake in that part of the board meeting during which the program is discussed and the final decision is made.

e. Finally yet importantly one should forbid all non-functional contact between the faculty of the program to be accredited (or its management), the members of the site-visit team and the members of the board of the accreditation organization during the process of accreditation. Such contacts are fateful for the integrity of the process.

Of course, one can make all kinds of objections to these solutions. The process runs the risk of becoming bureaucratized, there is no way to guarantee all this will work, and the problems will tend to move to other dark spots. However, in this case the first option of discarding the whole thing pops up again. If one supports the aims of accreditation, one should try to optimize the process in such a way that the probability of achieving those goals is maximized and the likelihood of $\alpha$ and $\beta$ errors is minimized.

\section{Conclusions}

This paper argued that there are a number of substantive challenges at stake in the accreditation of programs in public administration. These challenges refer, among others, to overconfidence in self-evaluations and the biases therein, the limited time of site-visit teams to investigate the truthfulness of such documents and the actual quality of programs and the ongoing discussions about the desirable nature of programs in public administration and the varying opinions of site-visit team members about essentials in PA programs.

Furthermore, accreditation of PA programs seems to have the image of being easily accessible, tolerant to different program missions and not too difficult in granting accreditation. As was concluded at the end of each of the previous sections, there are indications that although accreditation is intended to have many merits for the development, legitimacy and contents of programs in public administration education, there is an image of an ambiguous nature of public administration and of (inter-) national accreditation in this discipline being inclusive, instead of selective in establishing a company of institutes that upholds the values involved in the education in public administration.

This paper also argued that in practice these challenges are mostly adequately addressed, that it is not that difficult to distinguish between programs on which the 
advice should be to accredit them and programs preferably not to be accredited and that the conclusions of site-visit teams are most often unanimous.

Nevertheless, the advice of site-visit teams about accreditation is increasingly disputed. As far as it could be reconstructed, strategic arguments have gained momentum. The case study illustrated that the same arguments as used in discussions about substantial issues in accreditation processes within the discipline are abused as strategic arguments outside the discipline in order to induce $\alpha$ and $\beta$ errors.

We should search for solutions to resolve the pressing issues related to this problem. In the final analysis we proposed three options. The third one, pointing to the need to increase the transparency and checks and balances in the accreditation process seems especially auspicious.

\section{References}

Hajnal, György. 2003. "Diversity and Convergence: A Quantitative Analysis of European Public Administration Education Programs." Journal of Public Affairs Education 9, 245-258.

Morstein Marx, Fritz. 1967. "German Administration and The Speyer Academy." Public Administration Review 27, 403-410.

Pollitt, Christopher. 1996. "Antistatist Reforms and New Administrative Directions: Public Administration in the United Kingdom." Public Administration Review 56, 81-87.

Posner, P. L. (2009). The Pracademic: An Agenda for Re-Engaging Practitioners and Academics, in: Public Budgeting \& Finance, Vol. 29/1 pp12-26.

Raadschelders, Jos C. N. 2011. "The Study of Public Adminsitration in the United States." Public Administration 89, 140-155.

Reichard, Christoph. 2010. "Challenges of Public Administration Accreditation." Uprava 7/1-2, 37-51.

Rhodes, R. A. W. 1991. "Theory and Methods in British Public Administration: The View from Political Science." Political Studies 39, 533-554.

Robson, W. A. 1975. "The Study of Public Administration then and now." Political Studies 23, 193-201.

Stillman, J. Richard. 1997. "American vs. European Public Administration: Does Public Administration Make the Modern State, or Does the State Make Public Administration?" Public Administration Review 57, 332-338. 
Task Force on Standards of Excellence for Public Administration Education and Training. 2008. Standards of Excellence for Public Administration Education and Training. United Nations Department of Economic and Social Affairs/International Association of Schools and Institutes of Administration. Available at http://www.iias-iisa.org/iasia/e/Pages/default.aspx (last accessed 19-09-2013.

Waldo, Dwight. 1948. The Administrative State: A Study of the Political Theory of American Public Administration. New York: Ronald Press.

Wengert, E. S. 1942. "Public Administration: The Study of Public Administration." The American Political Science Review 36, 313-322. 